\title{
LIVROS DIDÁTICOS COMO FONTE/OBJETO DE PESQUISA PARA A HISTÓRIA DA EDUCAÇÃO NO BRASIL E NA ESPANHA
}

Os artigos que compõem o presente dossiê, de autores brasileiros e espanhóis, trazem em comum reflexões de historiadores da educação que utilizam o livro didático como fonte/objeto de investigação. Menosprezados e mesmo repudiados como algo que merecessem ser pesquisados, os livros didáticos adquiriram, a partir dos anos 1990, legitimidade no rol das investigações acadêmicas, não apenas na área de educação, mas em várias outras em que esse objeto está implicado. As abordagens sobre os livros didáticos, antes restritas à denúncia da presença insidiosa da ideologia (dominante, burguesa), expandiram-se em múltiplas direções: disciplinas, culturas e saberes escolares; metodologias e práticas de ensino; estética escolar, inscrita nas ilustrações e mesmo na diagramação das páginas; etc. O tema da diagramação inserese na perspectiva de se tomar o livro didático na sua materialidade, o que vale considerá-lo também como produto da indústria editorial numa sociedade capitalista. Essa mercadoria é, contudo, marcada por uma particularidade: a de atender a um mercado específico, o educacional, em que se mesclam políticas públicas de avaliação, seleção e aquisição dos livros e práticas de seus usos pelo público alvo, basicamente, professores e alunos.

Para esse crescimento multidirecional das pesquisas sobre livro didático, contribuíram certamente os grupos e os centros de pesquisa que foram se constituindo nos anos 1980 e 1990, à exceção do pioneiro Georg-Eckert Institute for International Textbook Research, fundado em 1975, na Alemanha. Na França, sob a coordenação de Alain Choppin, criou-se o Programme de Rechereches Emmanuelle, em 1980; a International Association for Research on Textbooks and Educational Media (IARTEM), com sede na Noruega, é de 1991; o Centro de Investigación MANES (Manuales Escolares), foi criado em 1992, na Espanha; o Centro Internacional de la Cultura Escolar (CEINCE), é de 2006, também na Espanha. No Brasil, a partir de 2004, desenvolveu-se o projeto Educação e Memória: Organização de Acervos de Livros Didáticos, sob a coordenação de Circe Bittencourt, cujas atividades se desdobraram em pesquisa, organização da Biblioteca do Livro Didático (BLD) e do banco de dados Livres (Livros Escolares).

As pesquisas desenvolvidas nesses centros e grupos foram criando uma cultura comum, com referenciais mais ou menos homogêneos, o que possibilitou intercâmbios proveitosos, projetos interinstitucionais, organização de eventos internacionais, etc. Desse modo, há hoje um consenso tácito de que o conceito de livro didático se refere a todos as publicações (impressos ou em outros suportes) produzidas para serem adotadas nas escolas para fins de ensino. Também já está distante o tempo em que os interlocutores de distintos países precisavam ajustar a nomenclatura do livro didático: manual escolar, na Espanha; libro de texto, na Argentina; textbook, nos países de fala inglesa; manuel scolaire, nos países francófonos; por exemplo. No Brasil, entre vários vocábulos (compêndio, livro de leitura, livro texto, etc.), acabou prevalecendo a expressão livro didático, consagrada 
no Decreto-Lei n. 1006, de 30/12/1938, que criou a Comissão Nacional do Livro Didático.

O presente dossiê é herdeiro dessa história. Não por acaso, conta com artigos de dois dos principais impulsionadores das pesquisas sobre os livros didáticos: Gabriela Ossenbah, responsável pelo Centro de Investigación MANES (Manuales Esoclares), da Espanha, e Agustín Escolano, coordenador do Centro Internacional de la Cultura Escolar, e responsável pela criação do neologismo "manualística", para designar o campo acadêmico de produção do saber que tem como foco os manuais escolares.

Composto de dez artigos, o dossiê conta com quatro primeiros que se dedicam a formular questões gerais em torno das pesquisas sobre o livro didático. "A manualística na Espanha: duas décadas de pesquisa (1992-2011)", de Agustín Escolano, apresenta um balanço das pesquisas sobre o livro didático na Espanha, em especial as realizadas no CEINCE, por pesquisadores de diversos países. Com o mesmo propósito de balanço, Gabriela Ossenbach apresenta "Considerações críticas sobre a pesquisa no campo da manualística após 20 anos de fundação do Centro de Pesquisa MANES”. As autoras Kira Mahamud e Ana Maria Badanelli propõem, com o artigo "O caderno escolar como objeto de estudo: uma aproximação aos avanços metodológicos em manualística", a investigação de cadernos escolares como extensão de objeto de estudos daqueles interessados em investigar o manual didático, como forma de otimizar a pesquisa manualística. Por fim, em "Livros didáticos de História do Brasil para o ensino secundário (1889-1950): procedimentos de localização, seleção e acesso", Kênia Moreira chama a atenção para a importância das questões metodológicas da pesquisa com livro didático.

Os seis artigos seguintes debruçam-se na análise de livro didático destinado a uma função ou disciplina escolar específica. Em "Os padrões dos livros de Lições de Coisas", Kazumi Munakata, utilizando-se de arquivos brasileiros, espanhóis e argentinos, dentre outros, questiona o padrão de linguagem dos livros de lições de coisas, considerando que, como método intuitivo, as lições de coisas pressupõem, como proposta pedagógica, o conhecimento direto com o mundo sensível e não pelos livros.

Lucilene Alcanfor, em "Produção e circulação dos livros escolares de Thomaz Galhardo: a série graduada "Na escola e no lar", e Felismina Silva, em co-autoria com Raquel Discini de Campos, em "A coleção didática 'As mais belas histórias' (1954-1976): lições sobre a formação do Brasil moderno", têm em comum o fato de elegerem como objeto de investigação um coleção didática para o ensino primário, o que significa analisar a produção de um autor e de uma editora. O primeiro circunscrito entre os séculos XIX e XX, em São Paulo, e o segundo, segunda metade do século XX, em Minas Gerais.

$\mathrm{O}$ artigo "O livro didático História do Brasil e a história a ser ensinada de Borges Hermida (1942-1971)", de Diogo Brauna, e "Manuais escolares, formação de professores e concepção clássica de modernidade: as 'noções de história da educação' de Afrânio Peixoto no Brasil na década de 1930", de Bruna Duarte e Décio Gatti Júnior, elegem como objeto de investigação um autor de livro didático, no primeiro caso, destinado ao ensino de História, e no segundo, ao ensino de História da Educação. Em "O uso do livro didático na primeira cadeira de Geografia e História da Província de São Paulo", Daniel Gomes analisa a institucionalização da aula de Geografia e História no período imperial, tendo como fonte o livro didático de Júlio 
Frank, destinado ao ensino secundário.

Elaborado com o propósito de fomentar a investigação acadêmica no campo da manualística em âmbito internacional, reunindo autores de espaços diversos de produção, que tem como tema comum o livro didático e a história da educação, esperamos ter alcançado nosso objetivo e desejamos a todos uma boa leitura.

Esta edição ainda é composta por três artigos em fluxo contínuo. O artigo "Desigualdades no Estado do Rio Grande do Sul: análise de indicadores sociais e educacionais", dos autores Evandro Ricardo Guindani, Yáscara Michele Neves Koga Guindani Sandro e Ben Hur Gonçalves do Nascimento busca comparar a realidade socioeconômica e a sua influência no contexto educacional, em municípios situados na fronteira, na região central e serrana do estado do Rio Grande do Sul.

Já o artigo "Saberes Docentes: o que revelam os trabalhos publicados nos Anais da Anped entre 2002-2013?”, de autoria de Nayenne Helsan Santos e Camila Alberto Vicente de Oliveira busca identificar as pesquisas sobre a temática nos referidos Anais e, especificamente, levantar a origem dos autores e os principais objetivos, metodologias e resultados apresentados nas respectivas publicações.

O último artigo em fluxo contínuo é intitulado "O Futuro estava Lá: o surgimento do Grupo Escolar Antônio João Ribeiro de Itaporã na região de Dourados (1953-1970)", das autoras Claudiani Rodelini e Maria do Carmo Brazil. O referido artigo apresenta os resultados da investigação realizada sobre o Grupo Escolar Antônio João Ribeiro de Itaporã, focando nas condições políticas e sociais decisivas para sua implantação, nas suas formas de funcionamento, bem como suas práticas cotidianas e dos distintos agentes sociais da comunidade entre os anos de 1953 e 1974.

E, por fim, a edição finaliza com a resenha de autoria de Thalita Pavani Vargas de Castro a respeito do livro "História da Escola Primária no Brasil: investigação em perspectiva comparada em âmbito nacional", de organização de Rosa Fátima de Souza, Antonio Carlos Ferreira Pinheiro e Antônio de Pádua Carvalho Lopes, publicado pela Editora Diário Oficial do Estado de Sergipe (Edise), no ano de 2015.

Profa..Dra. Kênia Hilda Moreira [UFGD]

Prof. Dr. Kazumi Munakata [PUC-SP]

Organizadores 